\title{
Blood Product Supply in Germany: The Impact of Apheresis and Pooled Platelet Concentrates
}

\author{
Karin Berger $^{a}$ Dorothee Schopohla Georg Wittmann ${ }^{b}$ Wolfgang Schramm ${ }^{c}$ \\ Helmut Ostermann ${ }^{\text {a }}$ Christina Rieger $^{\mathrm{a}}$ \\ a Department of Hematology/Oncology, University Hospital of Munich, Munich, Germany; \\ ${ }^{b}$ Department of Transfusion Medicine, Cell Therapeutics and Hemostaseology, University Hospital of Munich, Munich, Germany; \\ ${ }^{c}$ University of Munich, Rudolf-Marx-Foundation, Munich, Germany
}

\section{Keywords}

Antigen-matched platelets - Apheresis platelets . Donor pool · Pooled platelets · Red blood cell concentrates

\section{Summary}

Background: In Germany, about $60 \%$ of all produced platelet concentrates (PCs) are apheresis PCs (APCs). Ongoing discussions on APC reimbursement and costs might lead to a potential shift in pooled PC (PPC)/APC production. Objective of this analysis was to build a comprehensive model from the societal perspective to evaluate consequences associated with shifts in platelet supply and demand. Methods: Literature search, desktop researches on platelet supply and demand. Model calculations, time horizon one year: model input from the PaulEhrlich-Institute, data 2013 . Base case: $19.2 \%$ of annual whole blood donations (WBDs) were used for production of $38.5 \%$ PPCs, decay of 46,218 PCs $(8.0 \%)$. Scenarios calculated: variation in PPC proportion of $10-100 \%$. Results: Base case: during PPC production 41,957-83,913 red blood cell concentrates (RBCCs) are estimated to be lost, which corresponds to $1-2 \%$ of annual RBCCs in Germany. Scenarios were calculated for a production of $60-100 \%$ PPCs: loss is estimated to be $1.5-5.0 \%$ of annual RBCCs $(65,430-218,099)$, decay 54,189-69,022 PCs (9.4-12.0\%). Conclusion: Production of different blood components is interlinked and sensitive to unidimensional decisions. Increasing PPC proportion has negative impact on the RBCC production and on the antigen-matched APC donor pool. Completion of the model calculations to predict the optimal PPC/APC proportion would require evidence on the number of refractory patients, donor pool sizes, and incidences of diseases requiring platelet transfusions.

(c) 2016 S. Karger GmbH, Freiburg

\section{Introduction}

The production of pooled platelet concentrates (PPCs), apheresis platelet concentrates (APCs), red blood cell concentrates (RBCCs), fresh frozen plasma (FFP), and other blood components (e.g. blood coagulation factors) is interlinked. Changes in the production of one blood component may have consequences for the availability and quality of other components.

Data for platelet concentrate (PC) production in France, Germany, Switzerland, and the UK show that so far a significant percentage of produced PCs consists of apheresis platelets (table 1). Clinical guidelines do not differentiate between the application of PPCs or APCs except in patients with immune-mediated transfusion refractoriness and fetal and neonatal alloimmune thrombocytopenia (FNAIT). For those patients, single-donor apheresis platelets matched for human leukocyte antigens (HLA) and/or human platelet antigens (HPA) are recommended $[1,2]$. The incidence of FNAIT is one in 1,000 live births $[3,4]$. Studies focusing on hemato-oncological patients indicate that platelet refractoriness varies widely $(7-34 \%)$. The major cause for inadequate platelet increment in this patient collective originates from non-immunologic reasons like fever, infectious diseases, and sepsis with disseminated intravascular coagulation. Moreover, splenomegaly, bone marrow involvement, or cytoreductive chemotherapy also contributes to inferior transfusion success. Immunological causes for platelet refractoriness in hemato-oncology derive mostly from HLA alloimmunization which may be due to prior transfusions as well as prior pregnancy in female patients [5-7].

The fact that APCs generally are more costly compared to PPCs accelerates discussions around decreases in the production and supply of APCs. In 2014, the National Health Service Blood and Transplant (NHSBT) has released new recommendations for a reduction of apheresis production of platelets from approximately $80 \%$ to $60 \%$ of overall platelet provision by the end of $2015 / 2016$ [8, 9]. A clinical model was developed indicating that only about $40 \%$ 
Table 1. Platelet production in European countries

\begin{tabular}{|c|c|c|c|c|c|c|c|}
\hline \multirow[t]{3}{*}{ Country } & \multicolumn{4}{|c|}{ Proportion of PPC / APC production, number (\%) } & \multirow{3}{*}{$\begin{array}{l}\text { Changes in total } \\
\text { PC production } \\
2012-2013, \%\end{array}$} & \multirow{3}{*}{$\begin{array}{l}\text { Population-related } \\
\text { 2013, PCs / 1,000 } \\
\text { population }\end{array}$} & \multirow[t]{3}{*}{ Reference } \\
\hline & \multicolumn{2}{|l|}{2012} & \multicolumn{2}{|l|}{2013} & & & \\
\hline & pooled PCs & apheresis PCs & pooled PCs & apheresis PCs & & & \\
\hline France & $154,955(51.5)$ & $145,728(48.5)$ & $158,173(51.6)$ & $148,069(48.4)$ & +1.8 & 4.81 & {$[30-32]$} \\
\hline Germany & $226,206(38.4)$ & $362,709(61.6)$ & $222,228(38.5)$ & $355,365(61.5)$ & -1.9 & 7.15 & {$[13,33]$} \\
\hline Switzerland & $11,650(34.0)$ & $22,615(66.0)$ & $12,162(35.0)$ & $22,588(65.0)$ & +1.4 & 4.34 & {$[34-36]$} \\
\hline $\mathrm{UK}^{*}$ & $40,863(14.7)$ & $237,212(85.3)$ & $55,121(19.3)$ & $230,171(80.7)$ & +2.6 & 4.45 & {$[37-39]$} \\
\hline
\end{tabular}

Fig. 1. Model: influences on the proportion of PPCs and APCs required in the future. Reliable models of future PC supply and demand have to consider epidemiological data on PC demand, various aspects of PC production and the special demand of specific patients for single donor APCs. Aspects of future PC production are donor availability, WBDs and apheresis donations, losses of WBDs due to buffy coat production and subsequently

RBCCs, the size of the donor pool needed to provide sufficient HLA/HPA-typed platelets for specific patients, and the decay of PCs at the producer. Aspects of the demand of specific patients for APCs are the epidemiology of alloimmunization and FNAIT, the demand in pediatrics, and possible advantages of single-donor APCs for hemato-oncological patients.

single-donor apheresis platelets will be needed to satisfy current patient demands for the following specific patients: i) neonates and pediatrics and ii) patients requiring HLA/HPA matched platelets. The model is financially driven and should help to reduce costs and to implement platelet-additive solution for all PCs. Basis of the model is the assumption that there is no difference in clinical efficacy between apheresis or buffy coat-pooled platelets [8].

In Germany, health insurance companies are increasingly asking for a rationale when single-donor APCs instead of the less costly buffy coat PPCs are provided. This has become evident in a recent decision of the Federal Social Court (March 10, 2015; reference number B 1 KR 2/15 R). In this case, the statutory health insurance did not have to pay for the additional charge for APC transfusion in a cardiac surgery patient $[10,11]$. One of the major consequences of a decreasing proportion of APCs used will be that the donor pool for APCs will decline. For Germany in 2010, a total of 36,791 multiple apheresis donors with on average 5 apheresis donations/year were reported [12]. Matching patients with the appropriate HLA/HPA-typed platelets in the future will only be feasible with a sufficiently large pool of apheresis donors.
The focus of this paper is to analyze consequences associated with potential shifts in the supply and use of PPCs and APCs in Germany based on model calculations.

\section{Material and Methods}

\section{Model}

A model was designed to identify the parameters which influence future PC supply and demand and the proportion of PPCs and APCs required (fig. 1). German epidemiological data on PC demand, various aspects of PC production, and the special demand of specific patients for single-donor apheresis platelets were searched for by literature and desktop researches. Included issues of future PC production were amongst others donor availability, whole blood donations (WBDs) and apheresis donations, losses of WBDs due to buffy coat production, the size of the donor pool needed to provide sufficient HLA/HPAtyped platelets for specific patients, and rates of PC decay.

Model calculations from the societal perspective were conducted based on data from literature and desktop researches. An exemplary 1-year period was selected. The influence of the proportion in PPC and APC production on losses of quality and quantity of erythrocytes during buffy coat separation, on total PC decay at the producer, and on the availability of HLA/HPA typed donors was estimated. 
Table 2. Model input: base case*

\begin{tabular}{|c|c|c|c|c|}
\hline & \multicolumn{4}{|c|}{ Whole blood donations } \\
\hline & RBCs & total PCs & pooled PCs & apheresis PCs \\
\hline Production, n (\%) & $4,371,743(100)$ & $577,593(100)$ & $222,228(38.5)$ & $355,365(61.5)$ \\
\hline Decay at the producer, $\mathrm{n}(\%)$ & $98,945(2.26)$ & $46,218(8.00)$ & $26,552(11.95)$ & $19,666(5.53)$ \\
\hline
\end{tabular}

\section{Model Input}

PubMed was searched for data on PC supply and demand, on PPC and APC production and transfusion, on platelet refractoriness, on FNAIT, on HLA matching, and on platelet transfusions in hemato-oncological patients. The following searches were conducted: ('Platelet Transfusion/statistics and numerical data'[Mesh] OR 'Platelet Transfusion/therapeutic use'[Mesh] OR 'Platelet Transfusion/therapy'[Mesh] OR 'Platelet Transfusion/utilization'[Mesh]), 'Blood Donors'[Mesh] AND 'Germany'[Mesh], 'Thrombocytopenia, Neonatal Alloimmune'[Mesh], 'Platelet Transfusion'[Mesh] AND 'Immunosuppression'[Mesh], 'Platelet Transfusion'[Mesh] AND 'Leukemia'[Mesh]. In addition, free search terms, e.g. 'pooled platelets' AND 'apheresis platelets' as well as 'hematological malignancies' AND 'platelet transfusion', were applied. Each search was done for the last 10 years. Citations of identified journal articles were searched for further relevant publications. Desktop researches, predominantly internet searches for existing data, were performed. Model input data identified for calculations: Data from the Paul-Ehrlich-Institute (PEI) for the year 2013 on the production of PPCs and APCs in Germany were used [13]. Estimated losses of erythrocytes during production of PPCs were taken from the literature [14]

\section{Assumptions}

The following assumptions were made: i) There is no difference reported between PPCs and APCs concerning clinical efficacy $[1,2,8,15]$. ii) Four WBDs are needed for the production of 4 buffy coats to obtain 1 PPC [15-17]. iii) During buffy coat-derived PPC production from WBDs, a proportion of erythrocytes is lost or damaged. The estimated loss of erythrocytes amounts to $5-10 \%$ of the WBDs used [14]. WBDs are used for the production of RBCCs. In Germany, the yield of annual RBCCs from the annual WBDs in 2013 was $94.4 \%$ (table 2). Estimated losses in WBDs are converted in estimated final losses of RBCCs. iv) The decay rate at the producer for PPCs and APCs remains approximately stable as in 2013 (table 2) [13] v) APCs will continue to be needed for neonates, pediatric patients, and for patients requiring HLA/HPA matched platelets $[2-4,6,7]$.

\section{Base Case}

The model calculations for the base case describe the current situation for PPC/APC production in Germany. Base case calculations are based on data from the PEI for the year 2013 (table 2) [13].

\section{Scenarios}

Different scenarios were calculated. Proportions of PPCs were assumed to be $10 \%$ up to $100 \%$ of total PCs produced using the data from the PEI for the year 2013 [13].

\section{Model Output}

Model output is expressed as number of WBDs needed for the production of the corresponding amounts of PPCs, as percentage of annual WBDs used for production of PPCs, as the estimated number of WBDs lost annually due to the production of PPCs, as the estimated number of the calculated corresponding RBCCs lost annually, as the estimated percentage of annual RBCCs lost, and as the estimated decay of PCs at the producer in number of PCs and in percent of total PCs produced annually. The expected impact of changes in the proportion of PPCs produced on the pool of HLA/HPA-typed apheresis donors is addressed.

\section{Results}

In 2013, a total of $888,912 \mathrm{WBDs}$ were used to produce 222,228 buffy coat-derived PPCs in Germany. This corresponds to $19.2 \%$ of annual WBDs. The losses of erythrocytes in these WBDs used for buffy coat PPC production were estimated to amount to $44,446-$ 88,891 WBDs. This corresponds to $41,957-83,913$ RBCCs, which is an estimated percentage of annual RBCCs lost in Germany of approximately $1-2 \%$.

Calculations for different scenarios with a proportion of $10 \%$ up to $100 \%$ PPCs produced were conducted (table 3 ). Up to a proportion of $20 \%$ PPCs, no more than $10 \%$ of annual WBDs are used for buffy coat PPC production. The estimated percentage of annual RBCCs lost is $1 \%$ or below. The total decay of PCs at the producer is below 40,000 PCs ( $<7 \%$ of total PCs produced). With $60 \%$ PPCs produced, the estimated percentage of annual RBCCs lost increases up to $3.0 \%$. This corresponds to an estimated number of more than 130,000 RBCCs lost annually. A total of 54,189 PCs (9.4\% of total PCs produced) are lost due to decay at the producer. HLA/HPAtyped apheresis donors are reduced. With a change to $100 \%$ PPCs, overall $50 \%$ of annual WBDs have to be used for buffy coat production. This leads to an estimated percentage up to $5 \%$ of annual RBCCs lost and corresponds to an estimated number of more than 200,000 RBCCs lost annually. The number of PCs lost due to decay at the producer increases up to 69,022 (11.95\% of total PCs produced). In addition, the pool of HLA/HPA-typed apheresis donors disappears.

\section{Discussion}

Available data for Germany indicate that both types of platelet concentrates, buffy coat-derived PPCs as well as single-donor APCs, are needed to meet the requirements of a flexible and sufficient supply for all kinds of patients [16, 17]. Likewise, in 2011 the German Society for Transfusion Medicine and Immune Hematology already recommended to provide both types of platelets to avoid the hazards of critical shortage in platelet supply [18]. In this context extensive elaborations have been published on different aspects of the PC supply in Germany, e.g., on the quality of APCs compared to PPCs, on reimbursement, on the advantages of decentralized small apheresis donation units close to the hospital, or on the general possibility to shift the total supply to APCs but not to PPCs [11, 15-17, 19-21]. Still the question on the optimal proportion of PPC/APC production for Germany has not been answered. 
Table 3. Scenarios for different proportions of PPCs produced

\begin{tabular}{|c|c|c|c|c|c|c|c|c|c|c|}
\hline Percent PPCs of total PCs produced & 10 & 20 & 30 & 40 & 50 & 60 & 70 & 80 & 90 & 100 \\
\hline $\begin{array}{l}\text { Percent of annual WBDs used for } \\
\text { production of PPCs }\end{array}$ & 5 & 10 & 15 & 20 & 25 & 30 & 35 & 40 & 45 & 50 \\
\hline Estimated number of WBDs lost annually & $\begin{array}{l}11,552- \\
23,104\end{array}$ & $\begin{array}{l}23,104- \\
46,207\end{array}$ & $\begin{array}{l}34,656- \\
69,311\end{array}$ & $\begin{array}{l}46,207- \\
92,415\end{array}$ & $\begin{array}{l}57,759- \\
115,519\end{array}$ & $\begin{array}{l}69,311- \\
138,622\end{array}$ & $\begin{array}{l}80,863- \\
161,726\end{array}$ & $\begin{array}{l}92,415- \\
184,830\end{array}$ & $\begin{array}{l}103,967- \\
207,934\end{array}$ & $\begin{array}{l}115,519- \\
231,037\end{array}$ \\
\hline Estimated number of RBCs lost annually & $\begin{array}{l}10,905- \\
21,810\end{array}$ & $\begin{array}{l}21,810- \\
43619\end{array}$ & $\begin{array}{l}32,715- \\
65,430\end{array}$ & $\begin{array}{l}43,619- \\
87,240\end{array}$ & $\begin{array}{l}54,524- \\
109,050\end{array}$ & $\begin{array}{l}65,430- \\
130859\end{array}$ & $\begin{array}{l}76,335- \\
152669\end{array}$ & $\begin{array}{l}87,240- \\
174,480\end{array}$ & $\begin{array}{l}98,145- \\
196,290\end{array}$ & $\begin{array}{l}114,826- \\
218099\end{array}$ \\
\hline Decay at the producer: number of PCs & 35,649 & 39,357 & 43,066 & 46,774 & 50,481 & 54,189 & 57,898 & 61,606 & 65,314 & 69,022 \\
\hline
\end{tabular}

${ }^{\star}$ In Germany, total WBDs in 2013 were 4,631,290 used for the production of 4,371,743 RBCs (94.4\% of WBDs). Total production of PCs was 577,593 units [13]. It is assumed that losses of erythrocytes due to production of buffy coats for PPC production from WBDs amount to 5-10\% of the WBDs used [14]. The number of WBDs lost annually, as well as the corresponding number of RBCs otherwise produced from these WBDs can be calculated. As a function of the proportion of PPCs produced the percentage of WBDs used for production of PPCs changes. As a result also the estimated number and percentage of annual RBCs lost due to production of buffy coat derived PPCs are changed. Due to different rates of decay at the producer for PPCs and APCs the overall rate of platelet concentrate decay changes as well (table 2).

\section{Shifting the Supply from APCs to PPCs}

Ongoing discussions on increased cost of APCs over PPCs might lead to a potential shift in APC supply towards PPCs. In 2013 , the proportion of APCs produced was $61.5 \%$ in Germany, $80.7 \%$ in the UK, and $48.4 \%$ in France (table 1). Mainly driven by financial arguments the NHSBT has recommended in 2014 to reduce APC production stepwise to $60 \%$ of the overall platelet provision by the end of 2015/2016. In the UK, it has been estimated that only about $40 \%$ of APCs will be needed in the future for specific patients requiring HLA/HPA-matched platelets. However, one might speculate that the target $60 \%$ instead of $40 \%$ includes an ample safety margin to avoid risks on the side of the apheresis donor pool $[8,9]$.

To capture the consequences of changes in PPC/APC production in Germany we designed a comprehensive model. The base case describes the current situation of PPC/APC production in Germany with a proportion of $61.5 \%$ APCs in 2013 [13]. For the production of 222,228 buffy coat-derived PPCs, a total of $19.2 \%$ of the annual WBDs are used. During production of buffy coats for PPCs red blood cells are lost. In total, the calculated losses amount to $1-2 \%$ of all RBCCs which were donated that year. In scenario calculations we varied the proportion of APC/PPC provision. In case the proportion of APCs is lowered to $40 \%$ as has been recommended for the UK, the estimated loss of annual RBCCs during the production process of the $60 \%$ PPCs will increase up to $3 \%$. This corresponds to an estimated number of more than 130,000 RBCCs lost annually, 1.6 times as much as in the base case. Calculations with the assumption of stable decay rates at the producer result in an increase of PC decay from 46,218 PCs (8.0\%) for the base case to 54,189 PCs (9.4\%) with 60\% PPCs.

\section{Development of the Supply with WBDs}

In Germany, WBDs decreased from 2011 to 2012 by $3.2 \%$ and from 2012 to 2013 by $2.9 \%$ [13]. A concomitant reduction in RBCC consumption from 2010 to 2011 by $1.3 \%$, from 2011 to 2012 by $2.2 \%$, and from 2012 to 2013 by $6.5 \%$ was observed, presumably due to a more restrictive use of blood products and the introduction of the concept of 'patient blood management' [22]. Simultaneously, the number of WBDs per 1,000 inhabitants has decreased from 2011 to 2013 from 61 to 57, whereas the number of apheresis donations per 1,000 inhabitants still increased from 2011 to 2013 from 33 to 34 [13]. This indicates, in accordance with the predicted donor development in Germany in the upcoming years, that the restrictive use in blood products might not be sufficient to balance the decrease in WBDs and the subsequent decrease in the production of RBCCs in the future [12]. Expected demographic changes will lead to an aging population with a decreasing number of donors while an increasing number of cancer cases will increase the demand for blood products, especially PCs [23-25]. The shrinking process in the donor population has been predicted to accelerate, in particular after 2015 [23].

\section{Supply with HLA/HPA-Typed Platelets}

HLA/HPA-typed apheresis concentrates are indicated for transfusion refractory patients due to HLA antibodies and FNAIT [2, 3, $6,16,17]$. The shift to PPCs will lead to shrinkage of the HLA/ HPA-typed apheresis donor pool. This will be due to a decreased demand of apheresis donations and reduced recruitment of new apheresis donors. Currently, each apheresis center caring for these patients has built up a sufficiently large pool of donors to allow for timely delivery of matched APCs even for rare constellations. However, the number of apheresis donors needed to supply immediate HLA-matched APCs has not been defined. Therefore, it has not been incorporated into the model. It is obvious that substantial problems in achieving the supply of matched APCs can occur.

\section{Major Use of Platelet Transfusions in Hemato-Oncological Patients}

Few studies have been published so far on the epidemiology of PC use in terms of distribution of PCs to different patient groups evaluating the need for PPCs or APCs, [26]. One German singlecenter study showed that $56.6 \%$ of all PC transfusions (data for 
2011, apheresis only) were given to patients over 50 years of age. Hemato-oncological patients comprised $37.1 \%$ of all cases and received 50.9\% of transfused units of PCs [27]. A study on PC use in the North of England in 2012 showed similarly that $60.5 \%$ of PC transfusions were given to hemato-oncological patients. The median age of PC recipients was 57 years [28]. In our hospital, a total of 10,071 APCs were transfused in 2014 to 1,684 patients, thereof 5,613 APCs to 538 hemato-oncological patients (data on file, Department of Transfusion Medicine, Cell Therapeutics and Hemostaseology, University Hospital of Munich, ). A survey of the PEI regarding indications for PC transfusions in 2011 and 2012 showed that approximately $75 \%$ of all PCs were transfused in hemato-oncological departments including pediatric divisions [16, 17].

Immunosuppressed hemato-oncological patients require frequent PC transfusions and are prone to infections, allergic reactions, and alloimmunization [6]. Therefore, special subgroups of these patients, e.g. multitransfused leukemia patients or allogeneic hematopoietic stem cell transplantation recipients, might benefit from the use of APCs because of the lower exposure to antigens from a single donor with a possibly lower risk of allergic reactions and alloimmunization. However, prospective comparative studies on the use of APCs and PPCs in subgroups of these patients are currently rare or not available $[5,29]$.

\section{Limitations of the Model and Future Challenges}

The model was designed in a conservative way to avoid overestimations. Model assumptions were based on the scarce data published due to the lack of comprehensive evidence-based data. In consequence the following limitations arise and should be taken into consideration when interpreting the presented results: It was assumed that $4 \mathrm{WBD}$ are needed to obtain $1 \mathrm{PPC}$, even though for a certain percentage of the PPCs 5 or 6 buffy coats may be pooled. Due to the lack of representative information on the real number of WBDs used in Germany for the production of PPCs it might be possible, that the amount of red blood cells lost is higher than calculated in the model. Due to a lack of data, it was assumed on the basis of a published estimation that the loss of erythrocytes amounts to $5-10 \%$ of the WBDs used for PPC production. Therefore, the model can only give a range of the corresponding WBDs and RBCCs lost annually. The real number might be even higher. The decay rate at the producer for PPCs and APCs was assumed to remain stable. However, it might as well be the case that decay rates of PPCs decrease and decay rates of APCs increase when the proportion of PPCs to APCs changes to a preponderance of PPCs. Scientific papers have been published in the literature regarding risks of PPCs and APCs for recipients and donors [11, 15-17, 19-21]. The various safety aspects were not considered in the model. A comprehensive model should include data on efficacy and effectiveness of PPCs and APCs. However, so far no prospective randomized studies on clinical efficacy or comparative observational studies on the effectiveness of buffy coat PPCs and single-donor APCs have been published.

\section{Conclusion}

In conclusion, model calculations were provided to increase transparency on the sensitiveness in the context of blood production and blood supply. The impact of shifts in the production of PPCs and APCs on blood product supply in Germany was chosen as an example. To predict the optimal proportion of pooled PCs and single-donor apheresis PCs, reliable data are needed on PPC production, loss of erythrocytes, future PC demand, donor availability and future donations, donor pool required for HLA/HPA typed apheresis platelets, decay of pooled PCs and apheresis PCs, and demand of single-donor apheresis PCs for specific patients.

\section{Disclosure Statement}

The authors state that they have no conflicts of interest to disclose.

\section{References}

1 Slichter SJ: Evidence-based platelet transfusion guidelines. Hematology Am Soc Hematol Educ Program 2007:172-178

2 Executive Committee of the German Medical Association on the Recommendation of the Scientific Advisory Board, Bundesärztekammer (German Medical Association): Cross-Sectional Guidelines for Therapy with Blood Components and Plasma Derivatives-published by: Executive Committee of the German Medical Association on the Recommendation of the Scientific Advisory Board, 4th revised edition, 2009. www. bundesaerztekammer.de/downloads/Querschnittsleitlinie_Gesamtdokument-englisch_07032011.pdf (last accessed August 30, 2016)

3 Kamphuis MM, Paridaans NP, Porcelijn L, Lopriore E, Oepkes D: Incidence and consequences of neonatal alloimmune thrombocytopenia: a systematic review. Pediatrics 2014;133:715-721
4 Risson DC, Davies MW, Williams BA: Review of neonatal alloimmune thrombocytopenia. J Paediatr Child Health 2012;48:816-822.

5 The Trial to Reduce Alloimmunization to Platelets Study Group: Leukocyte reduction and ultraviolet B irradiation of platelets to prevent alloimmunization and refractoriness to platelet transfusions. N Engl J Med 1997;337:1861-1869.

6 Hod E, Schwartz J: Platelet transfusion refractoriness. Br J Haematol 2008; 142:348-360.

7 Pavenski K, Freedman J, Semple JW: HLA alloimmunization against platelet transfusions: pathophysiology, significance, prevention and management. Tissue Antigens 2012;79:237-245.

8 NHSBT Blood and Transplant 'Platelet Supply Project' July 31, 2014. www.nhsbt.nhs.uk/download/board papers/ july14/m14_74_Platelet_Supply_Project.pdf (last accessed August 30, 2016).
9 NHSBT Platelet Strategy 2011-2014 'Delivering for Patients and Donors' May 2011. www.nhsbt.nhs.uk download/board_papers/july11/platelet_strategy_board_ 2011.pdf (last accessed August 30, 2016).

10 Bundessozialgericht Urteil vom 10.3.2015, B 1 KR 2/15 R: Vergütung einer stationären Behandlung - Krankenhaus trägt das Risiko der kostengünstigen Verschaffung von Mitteln für eine erforderliche und wirtschaftliche Krankenhausbehandlung - Gewährung von Krankenhausbehandlung nach medizinischer Erfordernis. http://jurisbundessozialgericht.de/cgi-bin/ rechtsprechung/documentpy?Gericht=bsg\&Art=en\&n $r=13853$ (last accessed August 30, 2016).

11 Hitzler W, Hutschenreuter G, Wartensleben H: Risk assessment of single-donor (apheresis) platelet concentrates and pooled whole-blood-derived platelet concentrates (in German). Clin Lab 2015;61:869-875. 
12 Ritter S, Hamouda O, Offergeld R: Demography and donation frequencies of blood and plasma donor populations in Germany. Update 2010 and 5-year comparison (in German). Bundesgesundheitsbl Gesundheitsforsch Gesundheitsschutz 2012;55:914-922.

13 Paul-Ehrlich-Institut, Berichte nach $₫ 21$ Transfusionsgesetz (TFG) 'Tabellen Gewinnung, Herstellung, Import, Export und Verbrauch 2013 und Auswertungen über mehrere Jahre' 05.06.2014. www.pei.de/DE/infos/ meldepflichtige/meldung-blutprodukte-21-transfusionsgesetz/berichte/berichte-21tfg-node.html (last accessed August 30, 2016).

14 Zimmermann R, Blasczyk R, Zingsem J, Eckstein R, Heuft HG: Disparate risks and effects of pooled whole blood-derived vs. apheresis platelet production require an integral view on the blood supply. Vox Sang 2010; 99:295-296; author reply 297-298.

15 Schrezenmeier H, Seifried E: Buffy-coat-derived pooled platelet concentrates and apheresis platelet concentrates: which product type should be preferred? Vox Sang 2010;99:1-15

16 Mitteilungen des Arbeitskreises Blut des Bundesministeriums für Gesundheit «Bewertung von Aphereseund Pool-Thrombozytenkonzentraten». Bundesgesundheitsbl Gesundheitsforsch Gesundheitsschutz 2015;58:1126-1128.

17 Mitteilungen des Arbeitskreises Blut des Bundesministeriums für Gesundheit «Wissenschaftliche Erläuterungen zur Stellungnahme «Bewertung von Aphereseund Pool-Thrombozytenkonzentraten` des AK Blut vom 31.03.2015». Bundesgesundheitsblatt Gesundheitsforschung Gesundheitsschutz 2015;58:1129-1150.

18 Deutsche Gesellschaft für Transfusionsmedizin und Immunhämatologie e.V.: «Stellungnahme der Deutschen Gesellschaft für Transfusionsmedizin und Immunhämatologie zur Therapie mit Thrombozytenkonzentraten"' 19. Dezember 2011. www.dgti.de/docs/ doclink/10590/DGTI_Stellungnahme_TK_20111219. pdf (last accessed August 30, 2016).

19 Heuft HG, Mende W, Blasczyk R: A general change of the platelet transfusion policy from apheresis platelet concentrates to pooled platelet concentrates is associated with a sharp increase in donor exposure and infection rates. Transfus Med Hemother 2008;35:106113.

20 Vamvakas EC, Hitzler WE: Consistency and proportionality in policy decision-making in blood safety: the case for an all-apheresis platelet supply in Germany. Clin Lab 2013;59:1-22.
21 van der Meer PF: Apheresis versus whole-bloodderived platelets: Pros and cons. ISBT Science Series 2012;7:112-116.

22 Shander A, Javidroozi M: Blood conservation strategies and the management of perioperative anaemia. Curr Opin Anaesthesiol 2015;28:356-363.

23 Ehling M, Potzsch O: Demographic changes in Germany up to 2060 - consequences for blood donation. Transfus Med Hemother 2010;37:131-139.

24 Katalinic A, Peters E, Beske F, Pritzkuleit R: Projection of morbidity 2030 and 2050: impact for the national health system and blood supply. Transfus Med Hemother 2010;37:155-159.

25 Pritzkuleit R, Beske F, Katalinic A: Demographic change and cancer (in German). Onkologie 2010; 33(suppl 7):19-24.

26 Seifried E, Klueter H, Weidmann C, Staudenmaier T, Schrezenmeier H, Henschler R, Greinacher A, Mueller MM: How much blood is needed? Vox Sang 2011;100: $10-21$.

27 Geißler RG, Franz D, Buddendick H, Krakowitzky P, Bunzemeier H, Roeder N, Van Aken H, Kessler T, Berdel W, Sibrowski W, Schlenke P: Retrospective analysis of the blood component utilization in a university hospital of maximum medical care. Transfus Med Hemother 2012;39:129-138.

28 Charlton A, Wallis J, Robertson J, Watson D, Iqbal A, Tinegate H: Where did platelets go in 2012? A survey of platelet transfusion practice in the north of England. Transfus Med 2014;24:213-218.

29 Gurkan E, Patah PA, Saliba RM, Ramos CA, Anderson BS, Champlin R, de Lima M, Lichtiger B: Efficacy of prophylactic transfusions using single donor apheresis platelets versus pooled platelet concentrates in AML/ MDS patients receiving allogeneic hematopoietic stem cell transplantation. Bone Marrow Transplant 2007;40: 461-464.

30 Agence nationale de sécurité du médicament et des produits de santé (ANSM): 'Rapport d'activité hémovigilance 2013' onzième rapport des données nationales d'hémovigilance ANSM - Septembre 2014 http:// ansm.sante.fr/var/ansm_site/storage/original/applicatio $n / 8 a 2 c 3 c 478172 f c f b e 027742 a e d 130 a d f . p d f$ (last accessed August 30, 2016).
31 Agence nationale de sécurité du médicament et des produits de santé (ANSM) 'Rapport d'activité hémovigilance 2012' dixième rapport des données nationales d'hémovigilance ansm - Janvier 2014 http://ansm. sante.fr/var/ansm_site/storage/original/application/ b893629101bd8fdb10d446fabf34768b.pdf (last accessed August 30, 2016).

32 Statista: Frankreich: Gesamtbevölkerung von 2004 bis 2014 (in millionen Einwohner) http://destatista.com/ statistik/daten/studie/19298/umfrage/gesamtbevoelkerung-in-frankreich/ (last accessed August 30, 2016).

33 Statista: Bevölkerung - Entwicklung der Einwohnerzahl von Deutschland von 1990 bis 2014 (in Millionen). http://destatista.com/statistik/daten/studie/2861/ umfrage/entwicklung-der-gesamtbevoelkerung-deutschlands/ (last accessed August 30, 2016).

34 Jutzi M, Amsler L: Swissmedic HaemovigilanceBericht 2013, Sommer 2014. www.swissmedic.ch/ suchen/indexhtml?q=haemovigilance +2013 \&lang $=$ de (last accessed August 30, 2016).

35 Rüesch M, Jutzi M: Swissmedic HaemovigilanceBericht 2012, Sommer 2013. www.swissmedic.ch suchen/indexhtml?q=haemovigilance +2013 \&lang $=$ de (last accessed August 30, 2016)

36 Statista: Schweiz: Gesamtbevölkerung von 2004 bis 2014 (in Millionen Einwohner). http://destatista.com/ statistik/daten/studie/19317/umfrage/gesamtbevoelkerung-in-der-schweiz/ (last accessed August 30, 2016).

37 Public Health England (PHE): Safe supplies: Reflecting on the Population. Annual Review from the NHS Blood and Transplant/PHE Epidemiology Unit, 2013. 2014. www.gov.uk/government/uploads/system/uploads/ attachment_data/file/372598/NHSBT_PHE_Epidemiology_Unit_Annual_Review_2013.pdf (last accessed August 30, 2016).

38 Public Health England (PHE): Safe Supplies: Completing the Picture. Annual Review from the NHS Blood and Transplant/PHE Epidemiology Unit, 2012. 2013.www.gov.uk/government/uploads/system/uploads/ attachment_data/file/365683/NHSBT_PHE_Epidemiology_Unit_Annual_Review_2012_MASTER.pdf (last accessed August 30, 2016)

39 Statista: Großbritannien: Gesamtbevölkerung von 2004 bis 2014 (in Millionen Einwohner). http://destatista.com/statistik/daten/studie/19319/umfrage/ gesamtbevoelkerung-in-grossbritannien/ (last accessed August 30, 2016). 